\title{
$¿$ Resulta procedente una propuesta de armonización legislativa en el marco de la CAN, por el derecho a la pensión?*
}

\author{
Melisa Catherine Ferreira Amaya* \\ Diana Londoño Ospina**
}

Recibido: 6 de julio de 2016 • Aprobado: 5 de octubre de 2016

\section{Resumen}

El presente artículo pretende estudiar la viabilidad de una propuesta de armonización legislativa en materia pensional en el marco de la CAN con base en el principio integrador, rector de los países que conforman la unidad y por medio del cual se pretende fomentar el desarrollo equilibrado de los países miembros en condición de equidad, reflejada en la distribución equitativa, que permitirá trascender a una alianza que vaya más allá de lo económico y de esta manera permitir a los Estados miembros enfrentarse a los nuevos desafíos de la realidad mundial.

En ese sentido, en las presentes páginas se pudo determinar la importancia de la armonización legislativa en materia pensional en el marco de la CAN, estableciendo la naturaleza jurídica de dicha armonización legislativa, determinando su importancia en materia pensional y, finalmente, puntualizando los temas que podrán ser objeto de armonización legislativa frente al derecho a la pensión.

"El presente artículo es producto de la investigación "Armonización legislativa en el marco de la CAN, por el derecho a la pensión", por medio de la cual las autoras obtuvieron el título de especialistas en Derecho Administrativo de la Universidad Santo Tomás. DOI: http://dx.doi.org/10.15332/s19000448.2017.0046.05

** Abogada de la Uniciencia de Bucaramanga, especialista en Derecho Administrativo por la Universidad Santo Tomás. Correo electrónico: melissa_AT@hotmail.com

**a Abogada de la Universidad Católica de Colombia, especialista en Derecho Administrativo por la Universidad Santo Tomás. Correo electrónico: dianalondono24@hotmail.com 
El anterior ejercicio académico permitió adelantar una investigación con enfoque cualitativo mediante el método comparativo, por medio de la cual se pretendió captar la realidad jurídica que en materia pensional ocurre en los países que conforman la Comunidad Andina de Naciones.

Palabras claves: Armonización legislativa, pensión, Comunidad Andina, técnica legislativa.

\title{
IS IT APPROPRIATE A PROPOSAL FOR LEGISLATIVE HARMONIZATION IN THE FRAMEWORK OF THE CAN, FOR THE PENSION RIGHT?
}

\begin{abstract}
This article aims to study the feasibility of a proposal for legislative harmonization in pension matters within the CAN. This based on the integrating principle, rector of the countries that make up the unit and through which aims to promote the balanced development of member countries on condition of equity, reflected in the equitable distribution, which will transcend an alliance it goes beyond economic and thus allow member States face the new challenges of global reality.

In that sense, these pages could determine the importance of harmonizing legislation on pension matters within the framework of the CAN, establishing the legal nature of that legislative harmonization, determining their importance in pension matters and finally pointing out the issues that may be subject to legislative harmonization against the right to a pension.

The previous academic year, allowed to advance research with qualitative approach through comparative method, by which of which was intended to capture the legal reality that happens to pensions in the countries of the Andean Community of Nations. Keywords: Legislative harmonization, retiredmen, Andean Community, legislative technique.
\end{abstract}




\section{É PROCEDENTE UMA PROPOSTA DE HARMONIZAÇÃo LEGISLATIVA NO MARCO DA CAN PELO DIREITO À APOSENTADORIA?}

\section{Resumo}

Em este artigo busca estudar a viabilidade de uma proposta de harmonização legislativa em matéria de aposentadoria no marco da CAN baseada no principio integrador, reitor dos países que conformam a unidade e por meio do qual se pretende fomentar o desenvolvimento equilibrado dos países membros em condição de equidade, evidenciada na distribuição equitativa, que permitirá transcender a uma aliança além do econômico e de esta maneira permitir aos Estados membros se enfrentar aos novos desafios da realidade mundial.

Em este sentido, em estas páginas se conseguiu estabelecer a importância da harmonização legislativa em matéria de aposentadoria no marco da CAN, estabelecendo a natureza jurídica dessa harmonização legislativa, determinando sua importância no âmbito da aposentadoria e finalmente concretizando os temas que poderão ser objeto de harmonização legislativa frente ao direito à aposentadoria.

O anterior exercício acadêmico permitiu realizar uma pesquisa com enfoque qualitativo mediante o método comparativo, por meio da qual se pretendeu captar a realidade jurídica que no relacionado com a aposentadoria acontece nos países que conformam a Comunidade Andina de Nações.

Palavras-chave: Harmonização legislativa, aposentadoria, Comunidade Andina, técnica legislativa.

\section{Introducción}

El mundo actual se encuentra en constante cambio. Día a día surgen situaciones que originan la conformación de bloques que les permiten a los distintos países hacerse más fuertes de cara a la globalización. En razón de lo anterior, se hace necesario que dichos pueblos se unan no solo para la realización de acuerdos comerciales, pues también debe dotarse a los ciudadanos de instrumentos jurídicos idóneos para proteger sus derechos fundamentales, como la seguridad social, la vida digna y la igualdad, en procura de obtener un acceso a la pensión con ocasión de la labor desplegada a lo largo de sus vidas. Los países andinos no se encuentran 
exentos de la necesidad de dotar a sus ciudadanos de las mismas posibilidades al momento de acceder a la pensión, situación que se cuestiona en el presente artículo al observar la necesidad de consolidar un ordenamiento legal aplicable a toda la población en materia pensional.

El planteamiento jurídico por resolver busca contextualizar la importancia de acoger un criterio unificador en manera pensional por parte de los países andinos, el cual se reviste de relevancia en el marco de la CAN, ante la evidente disparidad en la que se encuentran los ciudadanos que efectúan su trayectoria laboral en varios pueblos andinos, y el estado de desigualdad frente a los países que manejan requisitos pensionales más ventajosos al momento de pedir la pensión.

Para el efecto, y como lo ha previsto Blanco: "La aspiración de la integración andina es el compromiso de los Estados andinos de consolidar intereses o valores comunes y la obligación de subordinación de los intereses nacionales a los valores e intereses comunitarios" (Blanco, 2010, p.1). Lo anterior resulta procedente en la actualidad a pesar de lo dispuesto por la profesora Cortés, quien ha considerado lo siguiente:

En Colombia ha existido un presidencialismo que histórica, constitucional y políticamente tiene unos rasgos propios, fundamentado en realidades sociales, culturales, políticas y económicas particulares. Un presidencialismo como forma de régimen constitucional, de origen democrático, que funciona dentro de una relativa regularidad institucional, que permite interacción de los partidos políticos, las instituciones y las libertades. (Cortés, 2013, p. 34).

En aras de dar respuesta al referenciado problema jurídico, se realizó un ejercicio académico por medio del cual se analizó la naturaleza jurídica de la armonización legislativa; adicionalmente, se estudió la importancia de dicha armonización en el marco del derecho a la pensión, todo lo anterior con base en la legislación interna de cada país. El problema jurídico planteado reviste de importancia para la Comunidad Andina, como quiera que entre otras prepara a la unidad frente al fenómeno de la globalización.

El estudio realizado permitió adelantar una investigación por medio de la cual se pretendió captar la realidad que en materia pensional ocurre en los países que conforman la Comunidad Andina de Naciones. De modo que esta investigación otorga un argumento consciente y fundamentado de la necesidad de unificar los 
requisitos pensionales como un paso a la unidad legislativa que debe revestir el marco laboral de los ciudadanos que trabajan en los países miembros de la Comunidad Andina de Naciones.

\section{La naturaleza jurídica de la armonización legislativa en el marco de la CAN}

Ante el proceso de globalización, surge la necesidad de crear alianzas integradoras que permitan a los Estados enfrentarse a los nuevos desafíos de la realidad mundial. Entre esos procesos integradores se encuentra la Comunidad Andina (CAN) que, por medio del Tratado de Cartagena suscrito en 1969, pactó la realización del Acuerdo de Integración Subregional con base en los principios de igualdad $^{1}$, justicia ${ }^{2}$ y paz, con el objetivo de fomentar el desarrollo equilibrado de los países miembros en condición de equidad, mediante la integración económica y social, reflejada en la distribución equitativa entre los suscriptores del tratado (Comunidad Andina, s. f.).

La CAN, tal y como lo dispone el artículo $7^{0^{3}}$ del mencionado acuerdo, nace con motivo de permitir la coordinación efectiva de sus miembros, para profundizar la integración subregional andina y, además, para promover la proyección externa y la consolidación de las acciones encaminadas al proceso de integración.

1 "Si las autoridades deben sometimiento a la Constitución y a la ley en el ejercicio de sus funciones, deben también sujeción al principio de igualdad que la propia Ley Superior prescribe: implícito en la obligación para las autoridades de sometimiento a la Constitución y la ley, se encuentra el deber de igualdad en el ejercicio de la función pública como mandato fundamental. En otras palabras, el deber de las autoridades de trato igualitario a las personas emana de la obligación general de acatamiento de la Constitución y la ley, inscrito en la noción de Estado de derecho. De este modo, desde el momento en que las autoridades administrativas juran el cumplimiento de la Constitución y de la ley -actos de legislación-, se encuentran obligados a la garantía de la igualdad legal de todos los ciudadanos, tanto en el ámbito de la administración pública como en la esfera de los procesos judiciales". ( Corte Constitucional, Sentencia C-816 de 2011).

2 "El principio de justicia material está relacionado con el principio de vigencia de un orden justo y, por ende, con el imperativo del Estado de promover ese orden y el deber de investigar y sancionar las infracciones a los deberes funcionales imputables a sus servidores". (Corte Constitucional, 2012).

3 “(...) finalidad, permitir una coordinación efectiva de los órganos e instituciones que lo conforman, para profundizar la integración subregional andina, promover su proyección externa y consolidar y robustecer las acciones relacionadas con el proceso de integración". (Acuerdo de Integracion Subregional Andino-Acuerdo de Cartagena). 
Dicho órgano es definido como una "Comunidad de derecho que exige, por parte de todos los Estados miembros, el sometimiento a un mismo derecho en aquellas materias en las que se ha realizado la transferencia del ejercicio de competencias en favor de la Comunidad" (Blanco, 2013, p. 174). Blanco lo define como una

\begin{abstract}
organización internacional cuya naturaleza jurídica es secundaria y funcional, por cuanto su subjetividad jurídico-internacional depende de la voluntad de los Estados y porque sus funciones o competencias se restringen a las que explícita o implícitamente les atribuyan los Estados miembros en el derecho primario u originario.
\end{abstract} (Blanco, 2013, p. 174).

Di Giovan lo presenta como una comunidad que supone un estatus jurídico en el cual los países que lo integran se desprenden de algunos privilegios intrínsecos de su soberanía, con la finalidad de generar una circunscripción dentro de la cual, por medio de la armonización de políticas bajo la tutela supranacional transiten sin restricciones y reciban el mismo trato las personas, los bienes y servicios ( $\mathrm{Di}$ Giovan, 1992).

Para lograr el fin integrador, la CAN permite presentar propuestas de armonización legislativa provistas de técnica legislativa, técnica que no solo establece reglas formales sobre la redacción de las disposiciones legales, sino que, además, se ocupa del contenido de sus mandatos frente a la unidad del ordenamiento jurídico. Dicho de otra forma, la técnica legislativa debe garantizar que la norma sea viable y eficaz desde su elaboración hasta su aplicación, con la coherente integración de los distintos ordenamientos, las diversas fuentes del derecho y su permanencia en el tiempo (Viver, 1996).

Por lo anterior, con la armonización legislativa se podrán superar obstáculos como la codificación, pues esta resulta insuficiencia para contener todas las materias; la tradición de considerar la ley como manifestación de la voluntad general, lo que resulta un "mito que se ha revelado falso, pues la ley, de suyo, no representa la voluntad general" (Núñez, 2009); y la incapacidad de la norma para enfrentarse al fenómeno de la globalización, en el que se plantean situaciones cada vez más volubles e inciertas que hacen impotente a la norma para afrontar las acciones globales, pues el proceso de globalización "se ha constituido en la muestra más importante de un proceso que no solo exporta y globaliza el derecho, sino que también produce alteraciones relevantes al imperio de la ley" (Blanco, 2013). 
Adicional a lo dispuesto anteriormente, se tienen dos creencias frente al detrimento de la calidad de la ley. La primera, medir la labor del legislador por la cantidad de proyectos de ley y los sancionados, lo que ha llevado a una

producción excesiva de leyes que han generado gran cantidad de reglamentaciones, propiciando inestabilidad jurídica, imposibilidad de conocer la ley, así esta se repute conocida, leyes producidas en su gran mayoría generales y ambiguas que contienen lagunas insanables gracias, en gran parte, a la ausencia de armonización y falta de sistematización en su elaboración. (Echeverri, 2009, p.11).

Esta puede reflejarse en confianza inversionista en mercados con mayor estabilidad jurídica. Solo las leyes solucionan problemas jurídicos de los países. "Que se revise de fondo el problema y que se generen soluciones creativas diferentes a la imposición de normatividades internas" (Blanco, 2010b, pp. 35-36).

Por lo tanto, en aras de lograr una normatividad con una mayor calidad en los países miembros, la CAN permite la configuración de propuestas de armonización legislativa, propuesta que es elaborada por el Parlamento Andino, "que es el órgano competente de formular propuestas de armonización legislativa a los países andinos con legitimidad" (Blanco, 2010b, p. 36) y que, además, debe garantizar la participación de todos los países andinos con motivo de mejorar el nivel de vida de la población, pues no basta con implementar políticas de desarrollo económico de los países miembros.

En consecuencia, la armonización legislativa se implementa con el objeto de unificar aquellos aspectos en que se tienen coincidencias normativas frente a derechos fundamentales como el derecho al trabajo, a la vida digna y al mínimo vital, en consonancia con los principios de equidad y justicia, que de manera conjunta confluyen en las garantías a situaciones que protejan el acceso a beneficios prestacionales de sus ciudadanos para obtener, tal como quedó plasmado en la Declaración de Tarija, del 12 de junio de 2007, un fortalecimiento de la democracia y un acercamiento social, político, económico y cultural.

En ese sentido, resulta relevante acudir a la armonización de la ley, pues hacerlo garantiza a los ciudadanos andinos la protección en igualdad de condiciones de sus derechos fundamentales y de las garantías mínimas en procura de mejorar sus condiciones de vida; además, es un instrumento que permite subsanar la ausencia de técnica legislativa de cada país, pues no existe la necesidad de acudir a la ley interna 
de los miembros de la unidad. Adicionalmente, ayuda a fortalecer el principio de seguridad jurídica y pugna por la defensa en la totalización de periodos cotizados en los países andinos.

\section{La importancia de la armonización legislativa en el marco del derecho a la pensión}

En líneas precedentes se enfatizó en la importancia de la armonización legislativa en pro de la materialización del fin integrador de los países andinos. Por lo anterior, y teniendo en cuenta que la armonización supone no solo reformar o crear leyes, sino que conmina a una adecuación en la vida de los ciudadanos que habitan en el territorio para lograr un desarrollo humano y comunitario, es allí donde nace la importancia de la armonización legislativa en materia pensional, pues se convierte en el escenario ideal para garantizar la igualdad entre los ciudadanos de los países miembros, para quienes

durante una etapa de la vida en que ya se ha cumplido con el deber social del trabajo y su fuerza laboral se ha visto disminuida, pues para ese momento de la vida se requiere una compensación por los esfuerzos realizados y la razonable diferencia de trato que amerita el haber alcanzado la vejez. (Corte Constitucional, 2011 a).

En este orden de ideas, se desarrollarán a continuación los principales fundamentos por los cuales se considera la proyección de una armonización legislativa en la temática del derecho a la pensión, los cuales se desplegarán de manera jerarquizada.

\subsection{Permite promover la igualdad del derecho a pensión para los ciudadanos que conforman los países andinos}

La Comunidad Andina emitió la Decisión 545 del 25 de junio de 2003, que "permite a los trabajadores andinos gozar de idénticos derechos que los trabajadores locales" e implementó decisiones relacionadas con la seguridad social, salud y seguridad de los trabajadores que se desplacen de un país miembro a otro, como puede evidenciarse de su artículo 13, literal f, pero con la cotización bajo las mismas condiciones del país al cual inmigran, lo que produce una situación de 
desigualdad respecto de los trabajadores locales, que gozan de garantías pensionales más favorables (Comunidad Andina, junio de 2007).

En igual medida, con la emisión de la Decisión No 583 de 7 de mayo de 2004, si bien el Consejo Andino propende hacia la unificación en materia de la seguridad social de los trabajadores de los países miembros en la manera como se proporciona la garantía de cotización a la seguridad social, no indica de manera expresa los requisitos a los que queda cubierto el trabajador, pues los parámetros requeridos para acceder a la pensión en cada país andino son diferentes (Comunidad Andina, s. f. b).

Por consiguiente, es innegable la situación de desigualdad en la que se encuentran los trabajadores que cotizan en diferentes países que componen la Comunidad Andina. Por tal razón, reviste gran importancia la armonización legislativa, porque con ella se garantiza el derecho a la igualdad, el cual tiene categoría fundamental, se encuentra contenido en el artículo 13 constitucional y consiste en "la igualdad frente a la ley como requisito indispensable en un Estado social de derecho" (Gómez, 2008, p. 62).

Es importante implementar una armonización legislativa en materia pensional porque se regulan de manera idéntica los requisitos para acceder a la pensión por parte todos los trabajadores, lo cual permite obtener un beneficio prestacional que no discrimina el país de origen o el lugar donde se desempeñan las distintas relaciones laborales a efecto de tener en cuenta los periodos cotizados, la edad y el ingreso base de liquidación para la pensión. Ello garantiza la igualdad de los trabajadores, independientemente del lugar donde estos presten sus servicios, en razón a que "una de las principales aplicaciones de la igualdad en el derecho del trabajo de antaño se enmarca en el conocido principio a trabajo igual, salario igual” (Jaramillo, 2010, p. 45).

\subsection{Suple la falta de técnica legislativa en materia pensional}

Todo proceso de armonización normativo debe estar provisto de técnica legislativa, la cual no solo debe establecer principios formales sobre la redacción de las disposiciones, sino también sobre el contenido de sus postulados, para garantizar así la unidad normativa y, a su vez, proporcionar reglas y criterios para alcanzar una integración concordante dentro de los diferentes ordenamientos jurídicos (Blanco, 2013). Con base en ello, la propuesta de armonización legislativa en el marco pensional entrará a suplir la falta de técnica legislativa que se encuentra 
presente en el ordenamiento jurídico interno de cada país como resultado de su contexto social, político e histórico enmarcado en un determinado periodo. Por ello, los Estados no pueden quedarse inertes ante el fenómeno de la globalización del mercado y la posibilidad de desplazarse de un lugar a otro, razón por la cual, es necesario implementar medidas como la unificación en materia pensional, que propende hacia la igualdad de derechos, proporcionando a todos los ciudadanos andinos la posibilidad de acceder a la prestación pensional indistintamente del lugar donde presten sus servicios, bajo los mismos requisitos.

\subsection{Fortalece el principio de seguridad jurídica}

Es una generalidad para los países andinos considerar que todo problema debe ser solucionado con la expedición de una nueva ley, lo cual evita "que se revise de fondo el problema y que se generen soluciones creativas diferentes a la imposición de normatividades internas" (Blanco, 2010b, pp. 35-36). Ello provoca una producción exagerada de normas que imposibilitan su conocimiento y que, además, resultan ambiguas, con vacíos y lagunas, lo que trae como resultado inseguridad e inestabilidad jurídica.

Este problema puede ser resuelto con el proceso de armonización legislativa, que trae consigo una mejora de la seguridad jurídica, la cual se define como

un principio que atraviesa la estructura del Estado de derecho y abarca varias dimensiones. En términos generales, supone una garantía de certeza. Esta garantía acompaña otros principios y derechos en el ordenamiento. La seguridad jurídica no es un principio que pueda esgrimirse autónomamente, sino que se predica de algo. Así, la seguridad jurídica no puede invocarse de manera autónoma para desconocer la jerarquía normativa, en particular frente a la garantía de la efectividad de los derechos constitucionales y humanos de las personas. (Corte Constitucional, 2002).

En consecuencia, podemos determinar que con la propuesta de armonización legislativa en materia pensional, se provee a la Comunidad Andina de seguridad jurídica, la cual surge como un principio que da certeza al tener una normativa integral en materia pensional, en aras de tener definida su situación jurídico-laboral al momento de trabajar en diferentes países miembros, de manera que se salvaguarden su estabilidad y cobertura respecto al acceso a su derecho pensional y se 
tenga en cuenta no solo la totalidad de los periodos cotizados, sino una igualdad de condiciones respecto de los demás trabajadores al momento de requerir beneficiarse con la pensión.

\subsection{Respuesta al fenómeno de la globalización}

La integración andina es un mecanismo pertinente para hacer jaque al proceso de globalización. En otras palabras, la integración andina es un mecanismo que permite a los Estados andinos matizar los efectos del fenómeno de la globalización. (Blanco, 2013).

Por lo anterior, y en aras de enfrentar los retos de la globalización, el desafío del proceso andino de integración debe ser lograr que los pueblos andinos se comprometan con la efectiva consolidación de la integración andina (Secretaría General de la CAN, 2008).

Frente a este fenómeno, las propuestas de armonización legislativa juegan un papel de gran importancia, ya que estas, con carácter vinculante, pueden facilitar el fin integrador. En este sentido, y para efectos del proceso andino de integración, la armonización legislativa permitirá preparar al pueblo frente al fenómeno de la globalización contextualizando el ordenamiento jurídico interno de los países miembros de cara a la globalización del derecho.

Por ende, en procura de fomentar esa integración y el fortalecimiento de los países andinos ante la globalización, también es pertinente dotar a sus ciudadanos de instrumentos jurídicos igualitarios que les permitan acceder a una pensión en las mismas condiciones a efecto de garantizar derechos fundamentales como la vida digna, el mínimo vital y la seguridad social.

\subsection{Protege los derechos al mínimo vital, la seguridad social y la vida digna}

En primer lugar, es del caso señalar la existencia de dos teorías respecto a las relaciones entre el derecho internacional y el derecho interno: la dualista y la monista. La primera considera el derecho internacional y el interno como dos sistemas de derecho iguales, independientes y separados, que no se sobreponen uno sobre el otro. La segunda prevé la prevalencia de la legislación internacional al interno. 
En la actualidad se busca la integración, tanto de las fuentes nacionales como de las internacionales, con el propósito de crear una unidad normativa (Monroy, 2001, p. 131).

Por lo tanto, es importante realizar esa unidad normativa respecto al acceso de pensión en los países miembros de la CAN, porque con ello se protegen los derechos al mínimo vital ${ }^{4}$, la seguridad social y la vida digna, que se concatenan en la manera como los ciudadanos, una vez llegan a la edad de retiro, indistintamente del país del cual provengan o en el que presten sus servicios, puedan subsistir en condiciones dignas y necesarias para llevar una vida digna, es decir, las condiciones mínimas requeridas para subsistir una vez cumplan su edad productiva.

En segunda medida, se precisa que, en el caso de Colombia, se prevén como fines del Estado el servir a la comunidad, en garantía de la efectiva de los derechos y deberes, facilitando la participación ciudadana, en defensa de la soberanía nacional, en procura del orden interno, en promoción de la prosperidad general y la protección de los ciudadanos en su vida, bienes, honra, creencias derechos y libertades (Gómez, 2008, p. 40).

En razón a lo anterior, es evidente que el Estado, como institución de carácter público que tiene como fundamento la satisfacción de las necesidades colectivas país, prevé la protección de los derechos fundamentales (Gómez, 2008, p. 27). Por consiguiente, los derechos al mínimo vital, la seguridad social y la vida digna deben resguardarse al revestir la condición de derechos fundamentales, situación que torna imprescindible para nuestro país, como miembro del CAN, propender hacia la unificación en las condiciones frente al acceso del derecho pensional.

Por lo tanto, la protección de los derechos anteriormente referidos se garantiza mediante la armonización legislativa, pues permite que los trabajadores accedan al beneficio económico prestacional para todos los ciudadanos que laboren en los países andinos, lo que origina una confianza en la aplicación de las normas y la efectividad frente al respeto de sus derechos.

4 "El concepto de mínimo vital, de acuerdo con la jurisprudencia, debe ser evaluado desde un punto de vista desde la satisfacción de las necesidades mínimas del individuo, por lo cual es necesario realizar una evaluación de las circunstancias de cada caso concreto, haciendo una valoración que se encamine más hacia lo cualitativo que a lo cuantitativo, verificándose que quien alega su vulneración tenga las posibilidades de disfrutar de la satisfacción de necesidades como la alimentación, el vestuario, la salud, la educación, la vivienda y la recreación, como mecanismos para hacer realidad su derecho a la dignidad humana”. (Corte Constitucional, 2011). 


\subsection{Fortalece la cohesión social}

A pesar de los esfuerzos de la CAN en las aproximaciones por la unificación en materia de seguridad social y pensional, tales esfuerzos no se han podido materializar en su esencia, pues lo que se busca como fin último es que sus ciudadanos puedan ejercer su fuerza de trabajo en cada uno de los países que conforman la unidad, permitiendo de esta manera llegar a una cohesión social que es definida como

la fuerza que se manifiesta en la decisión política de mantener unidos a los países que integran el órgano supranacional, compartiendo objetivos y poniendo en práctica unas políticas comunes tendentes a aproximar los valores de determinados indicadores económicos, sociales y territoriales representativos de la pertenencia a una entidad supranacional que aspira a que sus ciudadanos disfruten de similar nivel de vida, de bienestar y de oportunidades, cualquiera que sea el lugar en que se resida. (Lázaro, 2004, p. 191).

A su vez, para Carrasco (2000, p. 21), desde la perspectiva social, la cohesión significa que "hay semejanza o igualdad de oportunidades para acceder al empleo, a la formación, a la asistencia sanitaria, a la vivienda y a un medio ambiente de calidad, cualquiera que sea la región en que se viva".

En otras palabras, lo que pretende la cohesión social es un crecimiento de la calidad de vida de la población, expresado en mercado de trabajo y en la protección social (Lázaro, 2005). Es por eso que el espíritu de [esta] puede materializarse con la armonización legislativa en materia pensional al lograr que cada persona que ha puesto su capacidad de trabajo en un país o en otro, al final de su vida laboral pueda acceder a una pensión y de esta manera darle al proceso de integración una capacidad de coalición que va más allá de una mera alianza comercial (Navarro, 2000).

\section{Algunos temas que podrían ser objeto de armonización de legislación en el marco del derecho a la pensión}

Luego de determinar la importancia de la armonización legislativa en materia pensional, pasaremos a establecer aquellos temas que podrían ser objeto de dicha integración. Así las cosas, los temas que primordialmente revisten la necesidad de 
ser armonizados en el marco de la CAN son aquellos que determinan el reconocimiento pensional, que se enmarcan en la edad, el tiempo de servicio y las semanas cotizadas o los aportes realizados, requisitos comunes para el reconocimiento, pero que varían dependiendo del país donde se adquiera el derecho pensional. Es por ello que en los requisitos para obtener el derecho a la pensión surge la necesidad de la armonización frente al derecho a la prestación aludida.

Por lo anterior, se desarrollará a continuación cada uno de los elementos que revisten el reconocimiento de la pensión de vejez.

\subsection{La edad como requisito para acceder al derecho pensional en los países andinos}

La edad tiene relevancia a la hora de definir el derecho pensional, pues "la vejez es una contingencia que ha ido en aumento en las últimas décadas", lo anterior, con ocasión de los avances para extender el lapso de vida humana, situación que produce una circunstancia que debe observarse al financiar a largo plazo para determinar el beneficio prestacional (Abanto, 2015, p. 260).

La vida es una adaptación continua de las realidades tanto internas como externas, y el hombre realiza actos tendientes a resolverla. No obstante, muchas veces esos esfuerzos no alcanzan para ello. Por lo tanto, se adapta la norma, es decir, una noción o un sentimiento de justicia (Monroy, 2001, p. 311).

Definido lo anterior, y teniendo como punto de comparación el régimen pensional en Colombia, se advierte que este se subdivide en dos grandes vertientes que se excluyen entre sí, pero que son coexistentes: una corresponde al régimen de prima media con prestación definida, administrado por Colpensiones; y la otra corresponde es el régimen de ahorro individual con solidaridad, o fondos privados de pensiones (AA.VV. 2014, p. 47).

E1 Sistema General de Pensiones en ambos regímenes garantiza a sus afiliados y beneficiarios el cubrimiento de las siguientes contingencias: vejez, invalidez y muerte, respecto de las cuales se garantiza el derecho pensional, previos requisitos. De igual manera, contempla que, en caso de no cubrir el cotizante o sus beneficiarios los requisitos mínimos para acceder a la pensión, tendrán derecho a la devolución de sus aportes o a las indemnizaciones sustitutivas que correspondan (AA. VV., 2014, p. 48). 
Para el caso de la contingencia relacionada con vejez, se prevé una determinada edad como límite para acceder al beneficio pensional, como se procede a señalar.

En Colombia, las pensiones se rigen en la actualidad por la Ley 100 de 1993 (Congreso de la República de Colombia, 1993), con sus respectivas modificatorias, de modo que, de acuerdo con el artículo 33 de dicha ley, modificado por el artículo 9. de la Ley 797 de 2003 (Congreso de la República de Colombia, 2003), se fija la edad de 57 años para las mujeres y 62 para los hombres, a efecto de acceder a la pensión.

Por otro lado, en Perú se da un sistema mixto de pensiones. Existen dos sistemas de protección social. El primero es de carácter público y se denomina Sistema Nacional de Pensiones (SNP), regido por el Decreto Ley 19990 (Gobierno Revolucionario de Perú, 1973), que contempla que quien cuente con 65 años de edad tendrá derecho a pensionarse. No obstante, también existe el caso de la pensión anticipada, en el que también se prevé una edad de 50 años para las mujeres y de 55 años para los hombres, sin embargo, los somete a un número de semanas cotizadas. De igual manera, el sistema privado de pensiones prevé como edad para acceder a la pensión 65 años, indistintamente de lo cotizado, calculando el beneficio con el monto de lo aportado (Gobierno Revolucionario de Perù, 1973) .

En Bolivia, con la emisión de la Ley 065 de 2010 (Asamblea Legislativa Plurinacional de Bolivia, 2010), que reemplazó la Ley 1732 de 1996 (Congreso Nacional del Estado Plurinacional de Bolivia, 1996), basada en los principios de universalidad, sostenibilidad, solidaridad, equidad y eficacia, los regímenes pensionales se subdividen en a) régimen contributivo b) régimen semicontributivo y c) régimen no contributivo, en los que fijó la edad para pensión en 55 años para los hombres y 50 años para las mujeres .

Dicho país ha establecido cobertura en materia de seguridad social en el área privada. Respecto a la extensión a los migrantes, la reforma no los incluye, pues solo se limita a sus nacionales, empero, se expande a los trabajadores del sector informal y cubre los beneficios a largo plazo. Pero es necesario incluir medidas que cobijen a los migrantes respecto a la seguridad social (Arellano, 2013, p. 30).

Por su parte, en Ecuador, desde la promulgación de la Ley de 1942, la edad de expectativa de vida se encontraba en los 50 años aproximadamente, y en la actualidad se encuentra en 68 años para los hombres y 70 para las mujeres, manteniéndose la jubilación en 55 años, situación incide en el costo actuarial (Pazmiño y Rovalino, 2004, p. 18). 
Aunado a lo expuesto, se observa que por medio de la Ley 55 de 2001 (Congreso Nacional de Ecuador, 2001), denominada Ley de Seguridad Social, basada en los principios de solidaridad, obligatoriedad, universalidad, equidad, eficiencia, subsidiaridad y suficiencia, en Ecuador se prevé un régimen de jubilación por solidaridad intergeneracional y un régimen de jubilación de ahorro individual obligatorio, en el cual la jubilación de vejez se alcanza una vez se hayan cumplido 60 años de edad, fijando como edad mínima para acceder a quienes tengan el derecho pensional a partir de 2006.

Por lo anteriormente reseñado, se colige que en los países que conforman la CAN, la edad para que sus trabajadores accedan al derecho pensional no se encuentra unificada, pues mientras en Bolivia una mujer se pensiona a los $50 \mathrm{y}$ un hombre a los 55 años de edad, en Colombia deben esperar siete años más para obtener la edad requerida; la misma situación se observa en el caso de Perú, país donde la edad asciende a 65 años a efecto de obtener el derecho prestaciones; $y$ en Ecuador hasta los 60.

La situación anteriormente deducida demuestra la desigualdad respecto al acceso al derecho pensional entre los países que conforman el CAN, lo que evidencia las circunstancias de inequidad en material pensional en los países de lo componen, por ello se torna necesario manejar criterios unificadores dirigidos al desarrollo social y económico de estos y de sus ciudadanos.

Por lo expuesto, es claro que existen variaciones en el cumplimiento de la edad, lo que torna un evidente desequilibro en el acceso al beneficio de prestaciones entre los países miembros del CAN; luego, en aras de garantizar el desarrollo de dichas comunidades, también es necesario mejorar las condiciones de vida de sus connacionales. Por lo tanto, resulta evidente la necesidad de implementar reformas legislativas a fin de proteger el acceso a las condiciones dignas en materias pensionales a sus ciudadanos, al unificar la edad para acceder a la pensión.

\subsection{Semanas cotizadas o aporte económico para acceder a la pensión de vejez}

En términos generales, los sistemas de pensiones en los países que conforman la CAN se han organizado bajo esquemas contributivos, con aportes de empleadores, empleados, el Estado y fondos privados. Su diseño ha respondido al propósito de garantizar ingresos dignos en situación de vejez, invalidez o muerte (Uthoff, 2006). 
Estas contribuciones se configuran con las semanas de cotización, que pueden entenderse como el ahorro forzoso realizado por el trabajador durante toda una vida de trabajo, que le debe ser devuelto cuando haya perdido o vea disminuida su capacidad laboral como efecto del envejecimiento natural; ese reintegro se configura con la pensión de vejez.

El Colombia, para alcanzar la pensión es necesario contar con 1300 semanas de cotización; por su parte, en Perú se estima un periodo no inferior a 20 años; en Bolivia se consideran 120 cotizaciones durante la vida laboral; y en Ecuador, el aporte mínimo esde 360 cotizaciones a lo largo de la vida laboral, o bien, un mínimo de 480 contribuciones mensuales sin importar la edad (artículo 185 de la Ley de Pensiones).

Por lo anterior, el principal desafío hoy es el de lograr que los sistemas de pensiones incluyan de manera eficiente el financiamiento solidario, para combinar entonces esquemas contributivos y no contributivos bajo la lógica de la seguridad social. Es por esto que la armonización legislativa cobra importancia para los países miembros de la $\mathrm{CAN}$, logrando un régimen de contribución igualitario.

\subsection{La unificación respecto a la liquidación de la base para fijar la pensión}

En este punto es pertinente señalar que existen variaciones en la moneda que afectarían la tasación del ingreso base a la hora de fijar el monto de pensión. Concerniente a la devaluación, esta "ocurre cuando la moneda de un país reduce su valor en comparación con otras monedas extranjeras, razón por la cual el concepto de devaluación es completamente opuesto al de revaluación" (Subgerencia Cultural del Banco de la República, 2015).

Esa devaluación puede darse por varios motivos, no obstante, mayoritariamente ocurre al no haber "demanda de la moneda local o [cuando] hay mayor demanda que oferta de la moneda extranjera. Lo anterior puede ocurrir por falta de confianza en la economía local, en su estabilidad, en la misma moneda, etc." (Subgerencia Cultural del Banco de la República, 2015).

Los países andinos no están exentos de las crisis económicas que golpean a nivel global ni de los cambios en la devaluación o revaluación de la moneda. Sin embargo, con el fin de otorgar seguridad jurídica y condiciones igualitarias a los trabajadores en los distintos países de la CAN, es necesario efectuar una armonización en el 
salario base de liquidación pensional. Por lo tanto, es preciso abordar las distintas formas utilizadas en Perú, Bolivia, Colombia y Ecuador al momento de establecer dicha suma.

En Colombia, la pensión de vejez se liquida conforme al ingreso base de liquidación, correspondiente al $65 \%$, que se incrementará por cada 50 semanas en un $2 \%$, llegando a un $73 \%$, y luego de la semana 1200 se incrementa en un $3 \%$ hasta completar el monto máximo correspondiente al $85 \%$, monto límite que no podrá excederse ni ser inferior al salario mínimo legal mensual vigente (AA. VV., 2014, p. 45).

Por su parte, el régimen de ahorro individual contempla tres modalidades: renta vitalicia inmediata, retiro programado y retiro programado con renta vitalicia (AA. VV., 2014, p. 109). La pensión de vejez en este régimen será en la edad escogida por el cotizante siempre que el capital acumulado le permita obtener una pensión mensual superior al $110 \%$ del salario mínimo legal mensual vigente a la fecha de expedición de la Ley 100 de 1993 (Congreso de la República de Colombia, 1993), reajustado conforme al IPC, dependiendo el monto de la pensión del nivel de ahorro, de los rendimientos y de las variables, como el comportamiento de las tasas de interés y la edad en que decida pensionarse.

Del mismo modo, contempla que quien cumpla la edad de pensión y no hubiera acumulado el capital necesario para acceder a la pensión, tendrá derecho a la devolución del capital acumulado, incluidos los rendimientos financieros y el valor del bono pensional o a continuar cotizando hasta alcanzar el derecho (AA. VV. 2014).

Del mismo modo, en Perú, el Sistema Nacional de Pensiones, contenido en el Decreto Ley 19990, además del cumplimiento de la edad (65 años) y el aporte al sistema de pensiones por un periodo no menor a 20 años, fija como monto máximo de pensión de jubilación de "S/. 857.36, y un monto mínimo de pensión de S/. 415." (Gobierno Revolucionario de Perú, 1973).

Ahora, en cuanto a la pensión anticipada (50 años de edad para las mujeres y 55 años de edad hombres), una vez el individuo cuente con un mínimo de 25 y 30 años de cotizaciones al sistema, la pensión que se va a otorgar será la correspondiente al Sistema General de Pensiones, pero disminuida en un $4 \%$ por cada año de adelanto respecto a la edad de pensión (Ministerio de Economía Finanzas Perú, 2004, p. 3).

Ahora bien, la pensión de jubilación del sistema privado proporciona el derecho prestacional a partir de los 65 años de edad, sin que se exijan periodos mínimos de aportes, empero, el monto de la pensión corresponde al cálculo sobre la base de los 
aportes realizados y la rentabilidad generada en la cuenta individual de capitalización de cada afiliado. Como tasa de aportes se ha fijado el $8 \%$ de la remuneración asegurable. Se ha fijado una pensión mínima de S1 415 sin que exista una máxima. Dicho sistema también ofrece la opción de obtener la pensión adelantada ordinaria, que se otorga a aquellos cotizantes antes de cumplir los 65 años de edad, así como, el saldo acumulado más el valor de redención, que debe ser suficiente para la pensión calculada, cuyo mínimo pensional corresponderá al 50 \% del promedio de la remuneración de los últimos 10 años sin que exista un tope máximo (Ministerio de Economía y Finanzas, 2004).

Mientras tanto, para Bolivia, y de conformidad con la Ley 065 de 2010 (Congreso Nacional del Estado Plurinacional de Bolivia, 2010), se tiene que la pensión de vejez será igual o superior al sesenta por ciento (60\%) de su referente salarial de vejez $z^{5}$ Por su parte, en Ecuador el ingreso base para la cotización será el promedio de los cinco años de mejor salario sobre los cuales se aportó.

De lo expuesto se deduce que los trabajadores de los países andinos se encuentran ante una variedad de regímenes pensionales que varían dependiendo del país del cual provienen o en el que se desempeñen la labor, sin que puedan tener una visión general e igualitaria al momento de requerir la tasación de la pensión, pues esta varía en cada país de manera contundente, luego es preciso establecer medidas

${ }^{5}$ Ley 065 del 10 de diciembre de 2010. Artículo 8.- Condiciones de acceso. El asegurado accederá a la prestación de vejez cuando cumpla una de las siguientes condiciones:

a) Independientemente de su edad, siempre y cuando no haya realizado aportes al Sistema de Reparto $\mathrm{y}$ financie con el saldo acumulado en su cuenta personal previsional:

i. Una pensión igual o superior al sesenta por ciento $(60 \%)$ de su referente salarial de vejez.

ii. El monto necesario para financiar los gastos funerarios.

iii. La pensión por muerte para sus derechohabientes.

b) A los cincuenta y cinco (55) años hombres y cincuenta (50) años mujeres, siempre y cuando haya realizado aportes al Sistema de Reparto que le generen el derecho a una compensación de cotizaciones y financie con esta más el saldo acumulado en su cuenta personal previsional:

i. Una Pensión igual o superior al sesenta por ciento (60\%) de su referente salarial de vejez.

ii. El monto necesario para financiar los gastos funerarios.

iii. La pensión por muerte para sus derechohabientes.

c) A partir de los cincuenta y ocho (58) años de edad, independientemente del monto acumulado en su cuenta personal previsional, siempre y cuando cuente con una Densidad de aportes de al menos ciento veinte (120) periodos y financie un monto de pensión de vejez mayor al monto de la pensión solidaria de vejez que le correspondería de acuerdo con su densidad de aportes. 
tendientes a armonizar, lo anterior sumado al hecho de que las distintas monedas utilizadas en estos países varían de acuerdo con el fenómeno inflacionario, situación que permite una devaluación o revaluación de la pensión.

Así las cosas, es indispensable proveer una legislación unificada para los trabajadores de los países miembros de la CAN, que les proporcione una estabilidad real frente al acceso pensional.

\section{Conclusiones}

El proceso de integración andina es, sin duda, un mecanismo que permite hacer frente al proceso de globalización, el cual será más competente en la medida en que dicha integración se materialice no solo en cuanto al aspecto económico, sino político- jurídico-administrativo y social.

Para lograr ese fin último de integración, la CAN debe proveerse de instrumentos/mecanismos como la armonización legislativa, que le permitan alcanzar una verdadera cohesión social en pro de la coordinación efectiva de sus miembros, para profundizar en la integración subregional andina y, además, promover la proyección externa con un crecimiento de la calidad de vida de la población.

Con base en lo anterior, surge la importancia de la armonización legislativa en materia pensional, pues esta se convierte en el escenario ideal para garantizar la igualdad entre los ciudadanos de los países miembros que, durante una etapa de la vida en que ya han cumplido con el deber social del trabajo y cuya fuerza laboral se ha visto disminuida, requieren una compensación por los esfuerzos realizados y la razonable diferencia de trato que amerita el haber alcanzado la vejez y de esta manera darle al proceso de integración una capacidad de coalición que vaya más allá de una mera alianza comercial.

Se pudo determinar otra importante razón para implementar una armonización legislativa en materia pensional, pues con ella se reglamentarán de manera idéntica los requisitos para acceder a la pensión, lo cual permite obtener ese beneficio sin discriminar el país de origen o el lugar donde se desempeñan las distintas relaciones laborales, pues para tal fin serán unificados los criterios para establecer los factores determinantes para el reconocimiento de la prestación, como son los periodos cotizados, la edad y el ingreso base de liquidación, lo cual garantiza la igualdad de los trabajadores, independientemente del lugar donde estos presten sus servicios. 
Además, se pudo determinar cómo, mediante la plurimencionada propuesta de armonización, se provee a la Comunidad Andina de seguridad jurídica al tener una normativa integral en la citada materia y en aras de tener definida la situación jurídico-laboral de los ciudadanos andinos, salvaguardando su estabilidad y cobertura respecto al acceso a su derecho pensional, teniendo en cuenta no solo la totalidad de los periodos cotizados, sino una igualdad de condiciones respecto de los demás trabajadores al momento de requerir beneficiarse con la pensión.

De lograrse la unificación aquellos aspectos en los que se tienen coincidencias normativas frente a los derechos fundamentales, como el derecho al trabajo, la vida digna y el mínimo vital, en consonancia con los principios de equidad y justicia que de manera conjunta confluyen en las garantías a situaciones que protejan el acceso a beneficios prestacionales de sus ciudadanos, la democracia se verá fortalecida y se logrará un acercamiento social, político, económico y cultural que permitirá a los estados miembros de la unidad ser fuertes como subregión.

\section{Referencias}

Abanto, C. (2015). Regimenes complementarios de jubilación en el Perú. ¿nna opción paralela? Revista Derecho PUCP, 75, 253-282. Recuperado de goo.gl/t56I2w

Arellano, R. (2013). Marketing para vivir mejor. Gestion 2000 Perù,2016.

Asamblea Legislativa Plurinacional de Bolivia. (10 de diciembre de 2010). Ley n.o 065. Ley de Pensiones. Gaceta Oficial, edición 201NEC. Recuperado de Subgerencia Cultural del Banco de la República. (2015). Devaluación. Recuperado de goo.g1/UGmH9W

Blanco, C. (2010a). La importancia social y política del Parlamento Andino. Revista Via Inveniendi et Iudicandi, 6(1), 1-25. Recuperado de goo.gl/bqD7TS

Blanco, C. (2010b). Procesos de selección de contratos estatales: armonización legislativa en la Comunidad Andina CAN. Revista Verba Iuris, 15(24).

Blanco, C. (2013). La Comunidad Andina en el marco de lo jurídico y político. Revista Prolegómenos. Derechos y Valores, 16(31), 173-188. Recuperado de goo.g1/YHP4iN

AA. VV. (2014). Cartilla de seguridad social y pensiones 2014 (21. ${ }^{\mathrm{a}}$ ed.). Bogotá: Legis.

Cartilla de Seguridad Social y Pensiones. (2014). 21 edición Bogotá, Colombia.: Legis Editores.

Carrasco, E. (2000). La cohesión económica y social en la Unión Europea. Consideración del caso español. Madrid: Consejo Económico y Social - Civitas. 
Comunidad Andina. (s. f. a). Sistema Andino de Integración - SAI. Recuperado de http://www.comunidadandina.org/Seccionaspx?id=4\&tipo=SA\&title=siste ma-andino-de-integracion-sai

Comunidad Andina. (s. f. b). ¿Qué es la CAN? Recuperado de http://www.comunidadandina.org/Seccion. aspx?id=189\&tipo=QU\&title=somos-comunidad-andina

Comunidad Andina. (7 de mayo de 2007). Decisión 583. Sustitución de la Decisión 546, Instrumento Andino de Seguridad y Salud. Acordada en en marco de la XII Reunión Ordinaria del Consejo Andino de Ministros de Relaciones Exteriores. Guayaquil, Ecuador. Recuperado de goo.g1/5B9xgK

Comunidad Andina. (junio de 2007). Declaración de Tarija. Acordada en el marco de la XVII Reunión Ordinaria del Consejo Presidencial Andino, Tarija, Bolivia. Recuperado de goo.gl/SmC5ZU

Congreso Nacional del Estado Plurinacional de Bolivia. (29 de septiembre de 1996). Ley n. 1732. Ley de Pensiones. Gaceta Oficial, edición 561NEC. Recuperado de goo.g1/GPHSpc Congreso de la República de Colombia. (23 de diciembre de 1993). Ley 100 de 1993. Por la cual se crea el sistema de seguridad social integral y se dictan otras disposiciones. Diario Oficial 41.148 del 23 de diciembre de 1993. Recuperado de goo.gl/gRNsWv

. (29 de enero de 2003). Ley 797 de 2003. Por la cual se reforman algunas disposiciones del sistema general de pensiones previsto en la Ley 100 de 1993 y se adoptan disposiciones sobre los Regímenes Pensionales exceptuados y especiales. Diario Oficial 45.079 del 29 de enero de 2003. Recuperado de goo.gl/q10euh

Congreso Nacional de Ecuador. (30 de noviembre de 2001). Ley 55. Ley de Seguridad Social. Registro Oficial Suplemento 465 del 30 de noviembre de 2001. Recuperado de goo.g1/JtQGWm

Corte Constitucional. (2002). Sentencia T- 502/02. M. P. Eduardo Montealegre Lynett. Recuperado de http://www.corteconstitucional.gov.co/relatoria/2002/T-502-02.htm

Corte Constitucional. (2011a). Sentencia T-477/2011. M. P. María Victoria Calle Correa. Recuperado de http://www.corteconstitucional.gov.co/ relatoria/2011/T-477-11.htm

Corte Constitucional. (2011b). Sentencia T-581/11. M. P. Josè Ignacio Pretelt. Recuperado de http://www.corteconstitucional.gov.co/relatoria/2011/T-581-11.html

Cortés, S. (2013). Gobernabilidad y constitucionalismo: presidencialismo colombiano. Revista Verba Iuris, 2(30), 33-56.

Di Giovan, 1. (1992). Derecho internacional económico y relaciones económicas internacionales. Buenos Aires: Abeledo Perrot. 
Echeverri, D. (2009). Elementos básicos para mejorar la calidad de la normatividad andina dentro de la nueva visión estratégica de la CAN. Revista Rescate del Pensamiento Latinoamericano, Edición VI.

Gobierno Revolucionario de Perú. (30 de abril de 1973). Decreto-Ley n. ${ }^{\circ}$ 19990. Por medio del cual crea el Sistema Nacional de Pensiones de la Seguridad Social. Recuperado de goo.g1/IcMpVy

Gómez, J. (2008). Lineamientos constitucionales. Bucaramanga: Universidad Santo Tomás seccional Bucaramanga.

Jaramillo, I. (2010). Principios constitucionales y legales del derecho del trabajo colombiano. Bogotá: Editorial Universidad del Rosario.

Lázaro, L. (2004). España, la gran ampliación y la cohesión europea. Gaceta Sindical Reflexión y Debate, 4, 169-214.

Lázaro, L. (2005). Cohesión e integración: el modelo europeo. En J. B. Mata, (Coord.), C. F. Molina del Pozo y A. Faína (Dirs.), El diálogo entre los pueblos y las culturas en el marco de las relaciones eurolatinoamericanas: las perspectivas de las entiades subestatales. El caso de Galicia (pp. 187-223). Madrid: Dijusa.

Ministerio de Economía y Finanzas Publicas. Dirección General de Asuntos Económicos y Sociales. (mayo de 2004). Los sistemas de pensiones en Perú. Recuperado de https://www.mef.gob.pe/contenidos/pol_econ/documentos/sistemas_pensiones.pdf

Monroy, M. (2001). Introducción a derecho. Bogotá: Temis S. A.

Navarro, A. (2000). Integración Latinoamericana, La Estrategia de Cooperación, Bogotá: Universidad Externado de Colombia.

Núñez, M. (2009). La crisis del Estado. En J. Choza y J. De Garay (Eds.), Estado, derecho y religión en Oriente y Occidente (pp. 21-36). Madrid: Plaza y Valdés Editores.

Núñez, M. (2009). La crisis del Estado en Estado, Derecho y Religión en Oriente y Occidente. Recuperado de http://vlex.com/vid/65576105

Oficina de Normalización Previsional. (s. f.). Documento extraído el 3 de julio de 2016 https://www.onp.gob.pe/

Orellano, P. (2013). Características y desafíos de la migración para la seguridad social en la región latinoamericana. Revista Chilena de Derecho y Ciencia Politica, 4(1), 15-42. DOI: 10.7770/RCHDYCP-V4N1-ART448 http://portalrevistas. uct.cl/index.php/RDCP/article/view/448/440 http://bibliopolis.usta.edu.co/primo_library/libweb/action/display.do 
Pazmiño, S. y Robalino, G. (2004). La seguridad social en el Ecuador. Apuntes de Economía, 47. Recuperado de goo.gl/77uTvN

Pazmiño, S. y Robalino, G. (2004). Apuntes de economía dirección general de estudios. La seguridad social en el Ecuador. Quito, Ecuador. Recuperado de https:// contenido.bce.fin.ec/documentos/PublicacionesNotas/Catalogo/Apuntes/ae47.pdf

Presidencia de la República de Perú. (24 de abril de 1973). Decreto-Ley n. 19990. Por medio del cual del Gobierno Revolucionario crea el Sistema Nacional de Pensiones de la Seguridad Social. Recuperado de goo.gl/C2OeDT

Secretaría General de la CAN. (septiembre de 2008). Una Comunidad Andina para los ciudadanos: un proyecto para la integración integral de nuestros pueblos. Recuperado de goo.g1/BoI $89 \mathrm{O}$

Comunidad Andina. (24 y 25 de junio de 2003). Decisión 545. Instrumento Andino de Migración. Acordada en el marco de la XI Reunión del Consejo Andino de Ministros de Relaciones Exteriores de la Comunidad Andina. Quirama, Antioquia, Colombia. Recuperado de goo.g1/gfu $4 \mathrm{Pq}$

Uthoff, A. (2006). Brechas del Estado de bienestar y reformas a los sistemas de pensiones en América Latina (Serie Políticas Sociales n. ${ }^{\circ}$ 177). Santiago de Chile: CEPAL. Recuperado de goo.g1/6LEr9O

Viver, C. (1996). Técnica legislativa: estado de la cuestión y balance (provisional) de una década. Revista Autonomies, 21, 15-31. Recuperado de goo.g1/4jM09W 